\title{
Controlled, prospective trial of psychosocial function before and after continuous positive airway pressure therapy
}

\author{
T.A. McFadyen*, C.A. Espie*, N. McArdle ${ }^{\#}$, N.J. Douglas ${ }^{\#}$, H.M. Engleman ${ }^{\#}$
}

Controlled, prospective trial of psychosocial function before and after continuous positive airway pressure therapy. T.A. McFadyen, C.A. Espie, N. McArdle, N.J. Douglas, H.M. Engleman. (C) ERS Journals Ltd 2001.

ABSTRACT: The aim of the study was to investigate psychosocial function before and after continuous positive airway pressure (CPAP) therapy, and establish the determinants and consequences of objective CPAP use.

In a prospective, parallel-group study, changes in psychosocial scores were compared with conservative management or CPAP therapy for the sleep apnoea/hypopnoea syndrome (SAHS). Patient/partner couples from the top (CPAP treated, $n=44$ ) or bottom (conservatively treated, $n=25$ ) of a CPAP waiting list rated marital satisfaction (evaluation and nurturing relationship issues, communication and happiness (ENRICH), behavioural questionnaire), health/functional status (Short-Form-36 Health Survey, functional outcomes of sleep questionnaire) and sleepiness (Epworth sleepiness scale). Both groups' ratings at baseline were completed while on conservative therapy.

Baseline variables did not differ between groups. At follow-up, all seven summary psychosocial scores were statistically better in CPAP-treated patients, effect sizes (ES) ranging from moderate $(0.5 \mathrm{SD}$ : marital satisfaction) to very large $(>1.0 \mathrm{SD}$ : patients health, functional status and sleepiness scores). Scores in conservatively-treated patients deteriorated to a small or moderate degree (ES -0.2--0.7 SD), while those in the CPAP-treated group improved to a larger degree $(0.3-1.3 \mathrm{SD})$. Baseline polysomnographical and psychosocial scores, including marital satisfaction, did not predict objective CPAP use $(\mathrm{r}<0.3)$. CPAP use was modestly correlated $(\mathrm{r}=\mathbf{0 . 3 - 0 . 6 )}$ with improvement in all psychosocial areas.

Continuous positive airway pressure produced statistically and clinically significant psychosocial improvements, some of large magnitude, in psychosocial function. Determinants of usage were not identified, but benefits and usage were positively correlated.

Eur Respir J 2001; 18: 996-1002.
*Dept of Psychological Medicine, University of Glasgow, and "Edinburgh Sleep Centre, Dept of Medicine, University of Edinburgh, Edinburgh, UK.

Correspondence: H.M. Engleman Edinburgh Sleep Centre (Ward 48) Royal Infirmary Lauriston Place

Edinburgh

EH3 9YW

UK

Fax: 441315362362

Keywords: Marital satisfaction positive pressure therapy quality of life

sleep apnoea syndromes sleepiness

Received: January 292001

Accepted after revision July 102001

H.M. Engleman was supported by a fellowship from the British Lung Foundation.
Symptoms of the sleep apnoea/hypopnoea syndrome (SAHS) impact on many aspects of the daily behaviour and function of a patient, affecting marital and family relationships [1-3], work efficiency and income $[1,4]$, activity level [4-7] and general health and functional status [5, 8-17]. Controlled, prospective clinical trials employing validated psychosocial outcomes [12-17] have documented improvements in sleepiness and general health/functional status after continuous positive airway pressure (CPAP) therapy, but there have been no prospective controlled trials of changes in marital satisfaction. Quantitative comparisons of the magnitude of therapeutic effects across these related psychosocial areas are scanty.

A prospective, controlled, parallel-arm study of psychosocial function after CPAP therapy, incorporating validated outcome measurements of marital satisfaction, general health/functional status and sleepiness was therefore conducted. The primary aims of the study were to compare changes in psychosocial function in CPAP-treated patients with those in conservatively-treated patients, and to compare the magnitudes of therapeutic effects across psychosocial outcome measures. Secondary aims were to seek putative determinants of CPAP use from baseline demographic, polysomnographic and psychosocial scores, and putative consequences of CPAP use in psychosocial therapeutic benefits.

\section{Method}

\section{Trial design}

This trial was a repeated measures, parallel-arm, intention-to-treat study of conservative versus CPAP treatment in a clinical setting. Psychosocial questionnaires were mailed to patient/partner couples at baseline, when all patients were being managed conservatively with advice on weight loss, sleeping posture and avoidance of evening alcohol. "Conservative" patients were still receiving conservative management only when followed-up 3 months later. "CPAP" couples were followed-up 3 months after the patients' CPAP titration. Both subject groups were posted questionnaires on an intention-to-treat basis. The protocol was approved by the local ethics 
subcommittee, and written consent obtained from patients and their partners.

\section{Study participants}

Entry criteria for all patients were the clinical recommendation of CPAP, and cohabitation with a partner. A diary of CPAP-titration bookings provided the sampling pool, with questionnaire mailings to all eligible couples. Position on the waiting list acted as the group selection criterion. Couples booked for CPAP titration in 5-6 months were assigned to "conservative" follow-up, 3 months later. Those with a $<3$-month wait were assigned to "CPAP" follow-up, 3 months after titration.

Eligibility criteria were met by 142 patient/partner couples (CPAP: $n=97$, conservative: $n=45$ ), who were posted the study questionnaires with a request to participate in a study of symptoms in SAHS. Of these, 62 (44 CPAP, 18 conservative) were not included. A total of 27 , failed to return a valid consent form, 18 declined to participate, and 17 did not respond at baseline. A further 11 couples (9 CPAP, 2 conservative) failed to respond at follow-up, resulting in final sample sizes of 44 CPAP patients and 25 conservative patients. Demographic features of participating patients $(\mathrm{n}=69,23 \%$ female; mean age \pm sD was $50 \pm 10 \mathrm{yrs}$ and apnoea/hypopnoea index (AHI) $43 \pm 33 \cdot h^{-1}$ ) were not different from those of all CPAPrecommended patients at the Edinburgh Sleep Centre $(\mathrm{n}=389.18 \%$ female, mean age $51 \pm 12 \mathrm{yrs}$ and AHI $44 \pm 39 \cdot h^{-1}$; all $\left.\mathrm{p}>0.5\right)$.

\section{Outcome measurements}

Questionnaires of marital satisfaction were completed by patients and partners, and those of health and functional status and sleepiness by patients only.

\section{Marital satisfaction}

Evaluation and nurturing relationship issues, communication and happiness marital satisfaction scale. The evaluation and nurturing relationship issues, communication and happiness (ENRICH) marital satisfaction (EMS) scale [18] is a 15-item questionnaire providing a marital satisfaction score, corrected for idealistic distortion, for both partners in a marital relationship. Corrected scores are presented as normative percentile values [18].

Behavioural questionnaire. An in-house behavioural questionnaire asked subjects the frequency of bedsharing, the number of cuddles/hugs shared, and the number of disagreements or arguments within the past week.

\section{Healthlfunctional status}

Short Form-36 health survey. The Short Form-36 (SF36) questionnaire [19] is a generic 36-item measure of subjective health status, providing three summary scores for health transition, physical and mental components. The score range for health transition is $1-5$, and standardization provides population means \pm SD of $50 \pm 10$ for physical and mental component scores. The eight subscores (physical function, role-physical, role-emotional, bodily pain, social function, mental health, vitality and general health) range from $0-100$.

\section{Functional outcomes of sleep questionnaire}

The functional outcomes of sleep questionnaire (FOSQ) [5] provides a rating of sleepiness-related functional impairment, sensitive to impairment in sleep disorders. The FOSQ was administered in an abridged 26-item version (excluding the sexual activities subscale), with a total score range of 0-16. Subscores for the general productivity, social outcomes, activity level and vigilance scales each have a range of $0-4$. The sexual activities subscale was not administered lest this particular middle-aged Scottish population found its content too intrusive, and withdrew participation.

\section{Sleepiness}

Epworth sleepiness scale. The eight-item Epworth scale is a retrospective "trait" rating, widely used in clinical practice, of the likelihood of dozing in situations of different soporificity [7]. It has a total score range of $0-24$ and a normative mean \pm SD of $5 \pm 3$ [20].

Objective continuous positive airway pressure use. CPAPuse in patients were calculated from readings of the "on-time" counters of home CPAP units. These were obtained at the routine 3-month clinic follow-up or by telephone enquiry to patients. Total hours of use were divided by the number of days since issue, to produce an average daily running time for the units.

\section{Analysis}

Primary outcome variables (table 1) were the summary scores from the validated instruments (couples' marital satisfaction scores and patients' SF-36 health transition, physical component and mental component scores, FOSQ total and Epworth score). Variables of secondary interest (table 2) were also analysed to further elucidate group differences. These were unvalidated or subscore outcomes (couples' in-house behavioural ratings, and patients' SF-36 and FOSQ subscores).

The statistical significance of score differences between the treatment groups was assessed using the Mann-Whitney U-test, and within-group changes using Wilcoxons test. Clinical significance was evaluated by computing effect sizes (ES) (score difference/score SD) [21], to standardize and quantify therapeutic differences in psychosocial scores. The conservative groups' baseline SD was used as the common denominator for ES calculations, as appropriate for parallel-limb trials [16, 22]. ES were conventionally interpreted as representing 
Table 1. - Primary psychosocial outcome scores in continuous positive airway pressure and conservatively-treated groups

\begin{tabular}{|c|c|c|c|c|c|c|c|}
\hline \multirow[t]{2}{*}{ Primary outcome variables } & \multirow{2}{*}{$\begin{array}{l}\text { Direction of } \\
\text { improvement }\end{array}$} & \multicolumn{3}{|c|}{ Conservatives $^{\#}$} & \multicolumn{2}{|c|}{ CPAP } & \multirow{2}{*}{$\frac{\begin{array}{c}\text { Between } \\
\text { groups }\end{array}}{\mathrm{ES}^{f}}$} \\
\hline & & $\begin{array}{c}\text { Baseline } \\
\text { mean } \pm \text { SD }\end{array}$ & $\begin{array}{c}\text { Change } \\
\text { mean }\end{array}$ & W-S ES ${ }^{\S}$ & $\begin{array}{c}\text { Change } \\
\text { mean }\end{array}$ & W-S ES & \\
\hline \multicolumn{8}{|l|}{ Marital satisfaction } \\
\hline Patient ENRICH percentile & + & $55 \pm 6$ & -8.0 & $-0.50 * *$ & 5.0 & $0.31 *$ & $0.81 * *$ \\
\hline Partner ENRICH percentile & + & $54 \pm 18$ & -7.0 & $-0.39 * * *$ & 2.0 & 0.11 & $0.50 * *$ \\
\hline \multicolumn{8}{|l|}{ General health/functional status } \\
\hline SF-36 health transition score & - & $3.0 \pm 0.6$ & 0.4 & $-0.67 * *$ & -0.9 & $1.50 * * *$ & $2.17 * * *$ \\
\hline SF-36 physical component score & + & $38.6 \pm 8.8$ & -2.5 & $-0.28 *$ & 6.6 & $0.75 * * *$ & $1.03 * * *$ \\
\hline SF-36 mental component score & + & $41.1 \pm 9.7$ & -5.0 & $-0.52 * * *$ & 8.7 & $0.90 * * *$ & $1.41 * * *$ \\
\hline FOSQ total score & + & $9.6 \pm 2.9$ & -0.8 & $-0.28 * * *$ & 3.5 & $1.21 * * *$ & $1.48 * * *$ \\
\hline \multicolumn{8}{|l|}{ Sleepiness } \\
\hline Epworth score & - & $15 \pm 5$ & 1.0 & $-0.18 *$ & -6.0 & $1.28 * * *$ & $1.46 * * *$ \\
\hline
\end{tabular}

W-S: within-subjects; ES: effect size (score difference/SD); SF-36: Short Form-36 Health Survey; ENRICH: evaluation and nurturing relationship issues, communication and happiness; FOSQ: functional outcomes of sleep questionnaire. ${ }^{\#}: \mathrm{n}=25$; ๆ: $n=44 ;{ }^{s}$ : positive value represents improvement at follow-up; ${ }^{\prime}$ : positive value represents better improvement with continuous positive airway pressure than conservative therapy. ${ }^{*}: \mathrm{p}<0.05 ;{ }^{* *}: \mathrm{p} \leqslant 0.01 ;{ }^{* *}: \mathrm{p} \leqslant 0.001$.

clinically small $(0.25 \mathrm{SD}$ units $)$, moderate $(0.50 \mathrm{SD})$ or large $(0.75 \mathrm{SD})$ differences [21].

Two-tailed Spearman correlational analyses sought determinants of CPAP use from baseline demographical, polysomnographical and psychosocial variables. These were also used to seek putative psychosocial consequences of CPAP use.
All analyses were performed using SPSS for Windows, with alpha-significance values set at 0.05 . Prospective calculation showed the sample sizes provided $90 \%$ power to show "large" differences of $0.8 \mathrm{SD}$ between treatment groups (unequal groups; $n=69$ ), and $90 \%$ power to show "moderate" r-values of $\geqslant 0.5$ within the CPAP group $(n=44)$.

Table 2. - Secondary psychosocial outcome scores in continuous positive airway pressure (CPAP) and conservativelytreated groups

\begin{tabular}{|c|c|c|c|c|c|c|c|}
\hline \multirow{2}{*}{$\begin{array}{l}\text { Secondary outcome } \\
\text { variables }\end{array}$} & \multirow{2}{*}{$\begin{array}{l}\text { Direction of } \\
\text { improvement }\end{array}$} & \multicolumn{3}{|c|}{ Conservatives $^{\#}$} & \multicolumn{2}{|c|}{ CPAP } & \multirow{2}{*}{$\frac{\begin{array}{c}\text { Between } \\
\text { groups }\end{array}}{\text { ES }^{f}}$} \\
\hline & & $\begin{array}{l}\text { Baseline } \\
\text { mean } \pm \text { SD }\end{array}$ & $\begin{array}{l}\text { Mean } \\
\text { change }\end{array}$ & $\begin{array}{l}\text { W-S } \\
\text { ES }^{\S}\end{array}$ & $\begin{array}{l}\text { Mean } \\
\text { change }\end{array}$ & $\mathrm{W}-\mathrm{S} \mathrm{ES}^{\S}$ & \\
\hline \multicolumn{8}{|l|}{ Marital behavioural items } \\
\hline \multicolumn{8}{|l|}{ Patient } \\
\hline Bed-sharing nights $\cdot$ week $^{-1}$ & + & $5.4 \pm 2.6$ & -0.1 & -0.04 & 0.8 & $0.31 *$ & 0.35 \\
\hline Embraces' week $^{-1}$ & + & $5.6 \pm 4.1$ & -0.8 & -0.20 & 0.3 & 0.07 & 0.27 \\
\hline Disagreements' week $^{-1}$ & - & $0.8 \pm 1.0$ & 0.5 & $-0.50^{*}$ & -0.7 & $0.70 * * *$ & $1.20 * * *$ \\
\hline \multicolumn{8}{|l|}{ Partner } \\
\hline Bed-sharing nights $\cdot$ week $^{-1}$ & + & $5.4 \pm 2.7$ & -0.1 & -0.04 & 0.8 & $0.30^{*}$ & 0.33 \\
\hline Embraces $\cdot$ week $^{-1}$ & + & $5.2 \pm 4.4$ & -0.5 & -0.11 & -0.2 & -0.05 & 0.07 \\
\hline Disagreements· week $^{-1}$ & - & $0.6 \pm 1.0$ & 0.7 & $-0.70^{*}$ & -0.6 & $0.60^{* *}$ & $1.30 * * *$ \\
\hline \multirow{2}{*}{\multicolumn{8}{|c|}{$\begin{array}{l}\text { General health/functional } \\
\text { status subscores } \\
\text { SF-36 }\end{array}$}} \\
\hline & & & & & & & \\
\hline Physical function & + & $54 \pm 26$ & -7.0 & $-0.27 * *$ & 16.0 & $0.62 * * *$ & $0.88 * * *$ \\
\hline Role-physical & + & $31 \pm 36$ & -11.0 & $-0.31 * *$ & 31.0 & $0.86^{* * *}$ & $1.17 * * *$ \\
\hline Role-emotional & + & $45 \pm 46$ & -17.0 & $-0.37 * *$ & 21.0 & $0.46^{* * *}$ & $0.83 * * *$ \\
\hline Social function & + & $62 \pm 29$ & -1.0 & -0.03 & 18.0 & $0.62 * * *$ & $0.66^{* * *}$ \\
\hline Bodily pain & + & $74 \pm 27$ & -6.0 & $-0.22 * *$ & 6.0 & $0.22 *$ & $0.44 *$ \\
\hline Mental health & + & $63 \pm 20$ & -7.0 & $-0.35 * *$ & 13.0 & $0.65^{* * *}$ & $1.00 * * *$ \\
\hline Vitality & + & $32 \pm 19$ & -11.0 & $-0.58 * * *$ & 32.0 & $1.68 * * *$ & $2.26 * * *$ \\
\hline General health & + & $44 \pm 23$ & -2.0 & -0.09 & 16.0 & $0.70 * * *$ & $0.78 * * *$ \\
\hline \multicolumn{8}{|l|}{ FOSQ } \\
\hline General productivity & + & $2.6 \pm 0.8$ & -0.1 & $-0.13 * *$ & 0.7 & $0.88 * * *$ & $1.00 * * *$ \\
\hline Social outcomes & + & $2.5 \pm 1.0$ & -0.1 & $-0.10^{*}$ & 0.8 & $0.80 * * *$ & $0.90 * * *$ \\
\hline Activity level & + & $2.3 \pm 0.7$ & -0.1 & $-0.14 * *$ & 0.9 & $1.29 * * *$ & $1.43 * * *$ \\
\hline Vigilance & + & $2.2 \pm 0.8$ & -0.1 & $-0.13 *$ & 1.0 & $1.25 * * *$ & $1.38 * * *$ \\
\hline
\end{tabular}

W-S: within-subjects; SF-36: Short Form-36 Health Survey; FOSQ: functional outcomes of sleep questionnaire; ES: effect size. ${ }^{\#}: \mathrm{n}=25 ;{ }^{\uparrow}: \mathrm{n}=44$. ${ }^{\$}$ : positive value represents improvement at follow-up; ${ }^{f}$ : positive value represents better improvement with CPAP than conservative therapy. $*: p<0.05 ; * *: p \leqslant 0.01 ; * *: p \leqslant 0.001$. 


\section{Results}

\section{Between-group comparison at baseline}

Patients in conservative and CPAP groups did not differ in baseline demographic features or polysomnographic severity (table 3 ). None of the primary or secondary psychosocial scores, including Epworth sleepiness score, were different between groups at baseline.

\section{Between-group comparison at follow-up}

Primary outcomes. All seven primary psychosocial variables (table 1 and fig. 1) showed significantly better psychosocial function at follow-up in the CPAP than in the conservative group. ES for these ranged from the moderate to large, from 0.5-2.2 sD units.

ES for marital satisfaction scores were the smallest observed, but these suggested improvement of moderate or large size to the ratings of patients and partners, respectively. ES for summary scores of health/functional status and sleepiness all indicated large or very large between-group differences. The two largest between-group ES were produced from the single-item SF-36 health transition score and the FOSQ total score.

Secondary outcomes. Fourteen of 18 secondary outcome variables showed significantly better psychosocial function in the CPAP than in the conservative group, while none showed better function with conservative treatment (table 2). The only nonsignificant ES were patients' and partners' ratings for bed-sharing and embrace frequency.

All other psychosocial subscore ES showed advantages of at least moderate size with CPAP. Betweengroup ES were very large ( $>1 \mathrm{SD}$ ) for the frequency of marital disagreement, the SF-36 role-physical, roleemotional, mental health and vitality subscores and all FOSQ sleepiness subscores.

\section{Within-subject changes}

Primary outcomes. In conservatively-treated patients, all primary psychosocial variables showed significant deterioration of small to moderate ES $(-0.2-0.7 \mathrm{SD})$ (table 1 and fig. 1). These decrements were of small size

Table 3. - Background features of continuous positive airway pressure (CPAP) and conservatively-treated groups

\begin{tabular}{lcc}
\hline Features & Conservative* & CPAP $^{\#}$ \\
\hline Age yrs & $52 \pm 10$ & $49 \pm 10$ \\
Sex F:M & $6: 19(24 \% \mathrm{~F})$ & $10: 34(23 \% \mathrm{~F})$ \\
Apnoea/hypopnoea & $39 \pm 16$ & $46 \pm 40$ \\
index $\cdot \mathrm{h}^{-1}$ & & \\
\hline
\end{tabular}

Data are presented as mean \pm SD unless otherwise stated. *: $\mathrm{n}=25 ;{ }^{\#}: \mathrm{n}=44$. All comparisons (conservative versus CPAP and study sample versus all CPAP patients) nonsignificant $(\mathrm{p}>0.3)$.

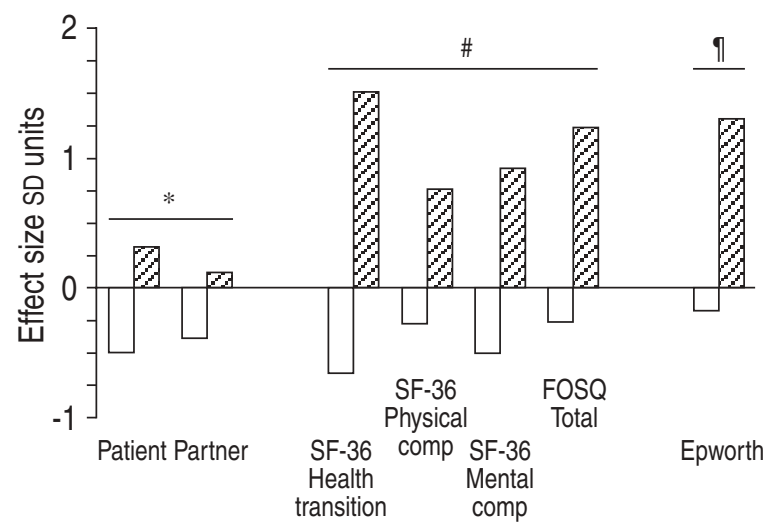

Fig. 1.-Therapeutic effect sizes for primary psychosocial outcome measurements. SF-36: Short Form-36 Health Survey; FOSQ: functional outcomes of sleep questionnaire; comp: component. *: marital satisfaction (evaluation and nurturing relationship issues, communication and happiness (ENRICH)); ${ }^{\#}$ : general health and functional status; ": sleepiness. $\square$ : conservatives; $\mathbb{Z}$ : continuous positive airway pressure. $\mathrm{p}<0.05$ for all within-group changes, except for the continuous positive airway pressure of the partner. $\mathrm{p}<0.05$ for all betweengroup differences.

for physical component, Epworth and FOSQ summary scores, and of moderate size for ratings of marital satisfaction, health transition and mental component summary scores.

In the CPAP group, all summary scores except partners' marital satisfaction showed significant improvement. The ES for therapeutic improvement in patients' marital satisfaction $(0.3 \mathrm{SD})$ was small, but the remaining five ES summary scores were large or very large $(>1.0 \mathrm{SD}$ : health transition, FOSQ and Epworth) in size.

Secondary outcomes. In conservatively treated patients, 12 of 18 secondary psychosocial outcomes worsened significantly at follow-up (ES -0.1--0.7 SD). Subscores that did not change significantly were couples bedsharing and embrace frequency and patients' SF-36 social function and general health scores. Deterioration of small size was observed in SF-36 physical function, role physical, role emotional and pain, and in all FOSQ subscores. Moderately sized decrements were seen for couples disagreement frequencies and patients SF-36 vitality scores.

In the CPAP group, all bar two outcomes (couples embrace frequencies) improved significantly (ES 0.2$1.7 \mathrm{SD})$. Small ES were observed in couples' bedsharing and patients' SF-36 pain ratings, and ES of moderate size in couples' disagreement frequency and the majority of SF-36 subscores. Large and very large ES were seen for SF-36 role physical, general health and vitality subscore, and for all FOSQ subscores.

\section{Objective continuous positive airway pressure use}

Mean rate of CPAP use in the CPAP group was 4.4 (sD 2.1) $\mathrm{h}^{\text {night }} \mathrm{n}^{-1}$, with $25 \%$ of patients using it for $\leqslant 3 \mathrm{~h} \cdot$ night $^{-1}$. 
Putative determinants of continuous positive airway pressure use

Within the 44 patients receiving CPAP, no significant correlates of objective use were found amongst baseline age, AHI, or primary psychosocial summary scores $(\mathrm{r}<0.2, \mathrm{p}>0.1)$. Associations between secondary psychosocial outcomes (behavioural FOSQ and SF-36 subscores) at baseline and subsequent CPAP use were also nonsignificant $(\mathrm{r}<0.28, \mathrm{p}>0.06)$.

Putative consequences of continuous positive airway pressure use

CPAP use correlated significantly and in the expected direction with changes in five of the seven primary psychosocial scores, linking greater use with larger score improvement (table 4).

Correlation coefficients for CPAP use and change in psychosocial function primary outcomes were all in the expected direction, explaining $10-32 \%$ of variance in these psychosocial score changes. Amongst these, partners' marital satisfaction was the weakest and FOSQ total the strongest correlate of subsequent CPAP use. Amongst secondary outcomes, significant correlates of objective CPAP use comprised: behavioural disagreement frequency $(\mathrm{r}=-0.4)$, all four FOSQ subscores ( $r=-0.5-0.6)$ and SF-36 subscores for vitality, social function and general health $(\mathrm{r}=0.3-5)$, these explaining 9-36\% variance in CPAP use.

\section{Discussion}

This prospective, controlled clinical trial used validated instruments to investigate psychosocial changes after CPAP or conservative therapy. Its findings corroborated those of previous controlled trials [11-17] of improved SF-36 and Epworth scores after CPAP, and showed for the first time in a controlled setting additional improvements in marital satisfaction [18] and sleepiness-related functional status [5].

The standardization of psychosocial scores as ES allowed the magnitude of therapeutic changes in these to be compared across treatments and across outcomes. Across treatments, summary scores reflecting

Table 4.-Putative consequences of continuous postitve airway pressure (CPAP) use ( $n=44$ CPAP users)

Primary psychosocial scores

CPAP use r-value

$\triangle$ Patient ENRICH

$\triangle$ Partner ENRICH

$\triangle \mathrm{SF}-36$ health transition

$0.31 *$

$\Delta \mathrm{SF}-36$ physical componen

$\Delta$ SF-36 mental component

$\triangle$ FOSQ total

$-0.42 * *$

$\Delta$ Epworth

$0.48 * *$

$0.57 * *$

$-0.46^{* *}$

ENRICH: evaluation and nurturing relationship issues, communication and happiness; SF-36: Short Form-36 Health Survey; FOSQ: functional outcomes of sleep questionnaire. $*: p<0.05 ; * *: p \leqslant 0.01$. marital satisfaction, health, functional status and sleepiness all favoured CPAP over conservative therapy. Score differences between treatments were of a size conventionally interpreted as representing a large clinical advantage for CPAP.

Across outcomes, marital satisfaction scores tended to improve less than health, functional status and sleepiness scores. Within-group ES segregated by treatment type, with broadly moderate decrements among the conservative group in all psychosocial summary scores, and broadly large improvements in the CPAP group, in all but marital satisfaction summary scores. The magnitude of differences in outcome ES may, in part, relate to whether these were assessed using generic or symptom-specific questionnaires. Generic questionnaires (ENRICH, SF-36) facilitate cross-disease comparisons [9], but they may be less sensitive than symptom-specific measures (FOSQ, Epworth). However, even generic primary outcomes (table 1) showed mostly "large" ES advantages with CPAP.

The correlational analyses explored potential psychosocial determinants and consequences of CPAP use. An association between partner influences and CPAP use had been suggested in a previous study [23]. However, baseline ENRICH scores were not linked to adherence in this sample, nor were any other polysomnographic or psychosocial variables, although largesample, long-term follow-up studies have suggested that the patients' disease [24, 25] and symptom [25] severity may partially determine acceptance of CPAP. Because adherence is behavioural and multifactorial, univariate correlations tend to be weak and below the threshold $(\mathrm{r}=0.5)$ for which the analysis was powered. The variability in findings from other studies of determinants of CPAP use, some observing suggestive relationships [26-28] and some, like this study, not [29], is compatible with such a profile.

However, like some previous correlational studies [4, 26-28], this investigation did suggest that increasing psychosocial benefits accrued with increasing CPAP use. These included greater benefit in partners' marital satisfaction and patients' general health, mental wellbeing, and sleepiness-related functional limitations. This provides grounds for targeting failing CPAP adherence for support and intervention wherever possible [23]. However, further studies are required to assess other psychological contributants to the patients' decision-making on CPAP acceptance and adherence.

Methodological shortcomings of this treatment study included a lack of randomization and blinding, exclusion of FOSQ sexual function subscale and a participation rate limited to $47 \%$. The treatment selection criterion replacing randomization was position on a CPAP titration list. This represented an accommodation of convenience to the demands of a clinical sleep service, but retrospectively appeared acceptably successful in yielding a demographically, polysomnographically and symptomatically homogeneous baseline population. This "smoothing" effect would be assisted by local practice of booking each diagnosed patient into the first available titration slot, so that position is determined by time since diagnosis 
more than disease severity. The deliberate omission of the FOSQ sexual function subscale reduced the sensitivity of this study to specific sexual aspects of psychosocial function. Further specialized sexual research in a suitable population could be of interest.

The lack of blinding in this study was a constraint imposed by clinical service restrictions, necessitating conservative management to bridge the waiting time until CPAP treatment could be provided. This may have resulted in differential demand characteristics in the treatment groups, with lower expectations of benefit on follow-up in conservatively managed patients than in those having received CPAP. Although this is a plausible explanation for at least some component of the moderately-sized psychosocial decrements seen in conservatively-treated patients, these could also reflect increasing symptomatology with objective disease deterioration over time [30].

The limited participation rate was typical of that for a postal study, but this also could have introduced sampling bias. However, more than one-third of nonparticipants were excluded as "responders" because of simple omission to identify themselves by signing the consent form. The response rate once adjusted for these is a more acceptable $66 \%$ of eligible participants. However, evidence of bias was not seen either in baseline comparisons between continuous positive airway pressure and conservatively-treated patients (table 1 and Results) or between the study sample and local continuous positive airway pressure patients (study participants).

Although this trial was compromised in some aspects by its accommodation within a local clinical pathway, its generalizability to the clinical setting was as a result enhanced. While blinded randomizedcontrolled trials are conducted in an experimental setting with treatments presented as equivalent, patients and practitioners in the clinical environment are increasingly well-informed of treatment choices, and they are frequently aware that resource restrictions limit access to treatments of choice. In this sample, the status of waiting for continuous positive airway pressure was associated with statistically and clinically significant deterioration in psychosocial scores of marital satisfaction, health and functional status and sleepiness. These quantitative outcomes, acquired in the clinical environment, could be incorporated as inputs to economic models of health service provision for sleep apnoea/hypopnoea syndrome [31], counterbalancing costs of quicker continuous positive airway pressure provision.

Acknowledgements. The authors would like to thank the patients and administrative, technical, nursing, medical and research staff of the Edinburgh Sleep Centre.

\section{References}

1. Grunstein RR, Stenlöf JA, Hedner JA, Sjöström L. Impact of self-reported breathing disturbances on psychosocial performance in the Swedish obese subjects (SOS) study. Sleep 1995; 18: 635-643.

2. Carter RD, Knight S. Silent partners: the wives of sleep apneic patients. Sleep 1987; 10: 244-248.

3. Kiely JL, McNicholas WT. Bed partners' assessment of nasal continuous positive airway pressure therapy in obstructive sleep apnea. Chest 1997; 111: 12611265.

4. Engleman HM, Asgari-Jirhandeh N, McLeod AL, Ramsay CF, Deary IJ, Douglas NJ. Self-reported use of CPAP and benefits of CPAP therapy. Chest 1996; 109: 1470-1476.

5. Weaver TE, Laizner AM, Evans LK, et al. An instrument to measure functional status outcomes for disorders of excessive sleepiness. Sleep 1997; 20: 835-843.

6. Hardinge FM, Pitson DJ, Stradling JR. Use of the Epworth sleepiness scale to demonstrate response to treatment with nasal continuous positive airway pressure in patients with obstructive sleep apnoea. Respir Med 1995; 89: 617-620.

7. Johns MW. A new method for measuring daytime sleepiness: the Epworth sleepiness scale. Sleep 1991; 14: $540-545$.

8. Briones B, Adams N, Strauss M, et al. Relationship between sleepiness and general health status. Sleep 1996; 19: 583-588.

9. Finn L, Young T, Palta M, Fryback DG. Sleepdisordered breathing and self-reported general health status in the Wisconsin sleep cohort study. Sleep 1998; 21: 701-706.

10. Smith IE, Shneerson JM. Is the SF-36 sensitive to sleep disruption? A study in subjects with sleep apnea. J Sleep Res 1995; 4: 183-188.

11. Jenkinson C, Stradling J, Petersen S. Comparison of three measures of quality of life outcome in the evaluation of continuous positive airways pressure therapy for sleep apnoea. J Sleep Res 1997; 6: 199204.

12. Engleman HM, Kingshott RN, Wraith PK, Mackay TW, Deary IJ, Douglas NJ. Randomized placebocontrolled crossover trial of CPAP for mild sleep apnea/hypopnea syndrome. Am J Respir Crit Care Med 1999; 159: 461-467.

13. Douglas NJ. Systematic review of the efficacy of CPAP. Thorax 1998; 53: 414-415.

14. Engleman HM, Martin SE, Deary IJ, Douglas NJ. Effect of CPAP therapy on daytime function in patients with mild sleep apnoea/hypopnea syndrome. Thorax 1997; 52: 114-119.

15. Ballester E, Badia JR, Hernández L, et al. Evidence of the effectiveness of continuous positive airway pressure in the treatment of sleep apnea/hypopnea syndrome. Am J Respir Crit Care Med 1999; 159: 495-501.

16. Jenkinson C, Davies RJ, Mullins R, Stradling JR. Comparison of therapeutic and subtherapeutic nasal continuous positive airway pressure for obstructive sleep apnoea: a randomised prospective parallel trial. Lancet 1999; 353: 2100-2105.

17. Redline S, Adams N, Strauss ME, Roebuck T, Winters M, Rosenburg C. Improvement of mild sleep-disordered breathing with CPAP compared with conservative therapy. Am $J$ Respir Crit Care Med 1998; 157: 858-865.

18. Fowers BJ, Olsen DH. ENRICH marital satisfaction 
scale: a brief research and clinical tool. J Fam Psychol 1993; 7: 176-185.

19. Ware JE, Snow KK, Kosinski M, et al. SF-36 health survey; manual and interpretation guide. Boston, Health Institute, New England Medical Center, 1993.

20. Johns M, Hocking B. Daytime sleepiness and sleep habits of Australian workers. Sleep 1997; 20: 844-849.

21. Cohen J. Statistical Power for the Behavioral Sciences. 2nd Edn. New Jersey, Erlbaum, 1988.

22. Kazis LE, Anderson JJ, Meenan RF. Effect sizes for interpreting changes in health status. Med Care 1989; 27: Suppl. 1, S178-S189.

23. Hoy CJ, Vennelle M, Kingshott RN, Engleman HM, Douglas NJ. Can intensive support improve continuous positive airway pressure use in patients with the sleep apnea/hypopnea syndrome? Am J Respir Crit Care Med 1999; 159: 1096-1100.

24. McArdle N, Devereux G, Heidarnejad H, Engleman HM, Mackay TW, Douglas NJ. Long-term use of CPAP therapy for sleep apnea/hypopnea syndrome. Am J Respir Crit Care Med 1999; 159: 1108-1114.

25. Krieger J. Long-term compliance with CPAP therapy in obstructive sleep apnea patients and in snorers. Sleep 1996; 19: S136-S143.

26. Bennett LS, Langford BA, Stradling JR, Davies RJ.
Sleep fragmentation indices as predictors of daytime sleepiness and nCPAP response in obstructive sleep apnea. Am J Respir Crit Care Med 1998; 158: 778 786.

27. Bennett LS, Barbour C, Langford B, Stradling JR, Davies RJ. Health status in obstructive sleep apnea: relationship with sleep fragmentation and daytime sleepiness, and effects of continuous positive airway pressure treatment. Am J Respir Crit Care Med 1999; 159: 1884-1890.

28. Kingshott RN, Vennelle M, Hoy CJ, Engleman HM, Deary IJ, Douglas NJ. Predictors of improvements in daytime function outcomes with CPAP therapy. Am J Respir Crit Care Med 2000; 161: 866-871.

29. Weaver TE, Kribbs NB, Pack AI, et al. Night-to-night variability in CPAP use over the first three months of treatment. Sleep 1997; 20: 278-283.

30. Pendlebury ST, Pepin JL, Veale D, Levy P. Natural evolution of moderate sleep apnoea syndrome: significant progression over a mean of 17 months. Thorax 1997; 52: 872-878.

31. Baumel MJ, Maislin G, Pack AI. Population and occupational screening for obstructive sleep apnea: are we there yet? Am J Respir Crit Care Med 1997; 155 9-14. 